\title{
SOIL PHOSPHORUS POOLS AND HARVEST EFFECTS ON SOIL SOLUTION CHEMISTRY IN THE MISSOURI OZARK HIGHLANDS
}

\author{
Gurbir Singh
}

Dr. Keith W. Goyne, Thesis Supervisor

\begin{abstract}
Forests ecosystems are governed by complex and dynamic nutrient cycles where soil is a major provider of nutrients essential for plant growth. Disturbances occurring in forested ecosystems (timber harvest, fire, and disease breakouts) lead to removal of living biomass which may impact nutrient cycling and can cause changes in soil solution chemistry, nutrient flux, and alter soil moisture and temperature. Missouri Ozark Highland soils are highly weathered and, to maintain long-term sustainability and productivity of forests supported by these soils, understanding harvest operations effect on nutrient loss is of utmost importance. Therefore, the primary objective of this study was to enhance understanding of nutrient dynamics and pools in forested soils of the Missouri Ozark Highlands. The study was divided into two specific research objectives: (1) quantify the influence of clearcutting (CC) and single tree selection forest (STS) regeneration on soil solution chemistry and nutrient flux in low and medium nutrient status soils at Missouri Ozark Forest Ecosystem Project (MOFEP); and (2) identify the importance of geomorphic and soil properties on total and available P concentrations in Ozark Highland soils.

To address concerns regarding the depletion of soil nutrients in association with timber harvest in the Missouri Ozark Highlands, soil solution and nutrient flux in low and medium nutrient status soils was monitored in clearcut, single tree selection, and no-harvest management sites (NHM) at MOFEP. Pre-harvest and post-harvest solution samples were collected with throughfall and zero-tension soil solution (ZTS) samplers (15 and $40 \mathrm{~cm}$ depths), and samples
\end{abstract}


were analyzed for $\mathrm{pH}$ and electrical conductivity (EC), anions $\left(\mathrm{F}^{-}, \mathrm{Br}^{-}, \mathrm{Cl}^{-}, \mathrm{NO}_{2}^{-}, \mathrm{NO}_{3}{ }^{-}, \mathrm{SO}_{4}{ }^{2-}\right.$, $\left.\mathrm{PO}_{4}^{3-}\right)$, cations $\left(\mathrm{K}^{+}, \mathrm{Na}^{+}, \mathrm{NH}_{4}^{+}, \mathrm{Ca}^{2+}, \mathrm{Mg}^{2+}\right.$, and total aluminum), dissolved organic carbon (DOC), and total nitrogen (TN). Ion exchange resin (IER) samplers (15 and $40 \mathrm{~cm}$ soil depths) were used to capture cumulative flux. Pre-harvest and one year post harvest soil samples were collected and analyzed for soil $\mathrm{pH}$, exchangeable concentrations of $\mathrm{Ca}^{2+} \mathrm{Mg}^{2+}$, and $\mathrm{K}^{+}$, effective cation exchange capacity (ECEC), base saturation (base sat.), extractable acidity (EA), extractable aluminum (EAl), aluminum saturation ( $\mathrm{Al}$ sat.), total organic carbon (TOC), and total nitrogen (TN). Post-harvest soil solution samples contained significantly greater concentrations of $\mathrm{NO}_{3}{ }^{-} \mathrm{Mg}^{2+}$, and TN and greater values of EC in the clearcut sites relative to STS and NHM. Mean daily flux measurements captured by IER samplers show significantly greater flux of $\mathrm{NO}_{3}{ }^{-}$ and $\mathrm{Mg}^{2+}$ in post-harvest clearcuts relative to pre-harvest measures. Despite morphological and some chemical differences between low and medium nutrient status soils, no influence of soil nutrient status was observed in this research. Study results demonstrate increased nutrient leaching after clearcutting but minimal changes were observed in STS harvested sites relative to control sites. Missouri forest managers may need to reevaluate and modify this practice to minimize the losses triggered after timber harvesting in order to maintain long-term sustainability and productivity of Ozark forests.

To meet the second objective, archived soil samples and soil characterization data were obtained for 50 pedons sampled at MOFEP. Soil chemical analyses were conducted to measure total $\mathrm{P}$, available $\mathrm{P}$, and citrate bicarbonate dithionite (CBD) extractable $\mathrm{Fe}, \mathrm{Al}$, and $\mathrm{Mn}$ in the samples studied. Linear regression and classification and regression tree (CART) analyses were applied to elucidate relationships between soil P pools and geomorphic and soil chemical properties. Total P and available P in the soils studied ranged from 15.55 to $410.13 \mathrm{mg} \mathrm{kg}^{-1}$ and 
3.81 to $30.61 \mathrm{mg} \mathrm{kg}^{-1}$, respectively. Linear regression analyses indicated a moderate correlation of CBD extractable Mn with total P $\left(r^{2}=0.77\right)$, Bray-1 available $P\left(r^{2}=0.69\right)$, and Mehlich-3 available P $\left(\mathrm{r}^{2}=0.71\right)$ for soils overlying Eminence bedrock. The CART analysis identified (1) CBD extractable Mn and total organic C as important variables explaining $39 \%$ of cumulative variation in total P; (2) CBD extractable Mn, and exchangeable Ca as important variables explaining $49 \%$ of cumulative variation of Bray-1 available P; and (3) CBD extractable Mn, and $\mathrm{pH}$ as important variables explaining $55 \%$ of cumulative variation of Mehlich-3 available P. This research aids in understanding and identifying locations in Missouri Ozark forests where of P pools may be relatively small, thus necessitating careful management and monitoring before and after timber harvest.

Results from the soil solution study and P forms enhance our understanding of nutrient leaching and budgets in Ozark Highland soils and can help better understand the impact of timber harvesting on nutrients in highly weathered soils. Study results will serve as a tool to better manage Missouri forests and to formulate future management policies. Furthermore this research can aid in identifying soils which are at risk of depletions for P concentrations after harvesting in Ozark highland landscape. 